\title{
A Study on Prevalence of Serum Resistant \& Sensitive Escherichia Coli in Urinary Tract Infection
}

\author{
K. Prakash ${ }^{\odot 1}$, J. Shravan Kumar ${ }^{\circledR 2}$, J. Rajamouli ${ }^{\circ}$, Sachin Gurnule ${ }^{\odot 4}$ \\ ${ }^{1}$ Associate Professor, Department of Microbiology, CAIMS, Karimnagar, Telangana, India, ${ }^{2}$ Assistant Professor, Department of Surgery, Prathima Institute of Medical \\ Sciences, Karimnagar, Telangana, India, ${ }^{3}$ Professor \& HOD, Department of Microbiology, CAIMS, Karimnagar, Telangana, India, ${ }^{4}$ Statistician Cum Lecturer, Department \\ of Microbiology, CAIMS, Karimnagar, Telangana, India.
}

\section{Abstract}

Background: Escherichia coli is the commonest organism causing urinary tract infection in women and children especially in those with uncomplicated infections. It has been traditionally described Serotypes of Escherichia coli were consistently associated with Uropathogenicity and designated as Uropathogenic Escherichia coli.It is now recognized that a subset of fecal Escherichia coli can be colonized in the peri-urethral area, enter the urinary tract and cause symptomatic disease. These are currently defined as Uropathogenic Escherichia coli. The aims \& objectives are to the isolation of Escherichia coli in Urinary tract infection. 2. To determine the prevalence of Serum resistant Uropathogenic Escherichia coli. 3. To compare antimicrobial efficacy in Serum resistant and Serum sensitive Uropathogenic Escherichia coli. Subjects \& Methods: An observational study was conducted on 100 patients and urine samples collected from suspected and suffering from urinary tract infection. Study period from August 2018 to July 20019 attending General medicine OP in Hospital. Escherichia coli were isolated and identified by conventional techniques Mackie \& Mc Cartney. The strains were subjected to multiple drugs to study serum resistance and sensitivity. Results: From 100 urine samples 71 Uropathogenic, 18 males \& 53 females. 40\% Sero-resistant and 60\% Sero-sensitive among them 2 to 18 years males and $>40$ years females resistant, above 40 years males and 19 to 40 years females are sensitive to multiple antibiotics. Conclusion: it emphasizes Serum resistance is an important virulence factor, It may lead to pyelonephritis and septicemia. Serum resistant E. coli are multiple drug-resistant, so the present study formulating guidelines for planning effective treatment and Periodic surveillance to monitor resistance.

Keywords: Uropathogenic, Resistant, Sensitivity.

Corresponding Author: J. Shravan Kumar, Assistant Professor, Department of Surgery, Prathima Institute of Medical Sciences, Karimnagar, Telangana, India.

E-mail: jann.shravan@gmail.com

Received: 02 July 2020

Revised: 18 August 2020

Accepted: 26 August 2020

Published: 30 December 2020

\section{Introduction}

Escherichia coli is the commonest organism causing urinary tract infection in women and children especially in those with uncomplicated infections. The urinary tract is among the most common site of bacterial infection both in community-based and hospitalized patients. In Escherichia coli, virulence results from the cumulative impact of several special properties or virulence factors, which serve to distinguish potential pathogens from harmless intestinal strains. The virulence of individual strain in a given infection is determined by the presence and actual expression of the virulence genes present in them and also by the environmental conditions in the host. ${ }^{[1]}$ It has been traditionally described that certain serotypes of Escherichia coli were consistently associated with Uropathogenicity and were designated as Uropathogenic
Escherichia coli (UPEC). ${ }^{[2]}$

It is now recognized that there is a subset of fecal Escherichia coli that can be colonized in the periurethral area, enter the urinary tract and cause symptomatic disease. These are currently defined as Uropathogenic Escherichia coli. Virulence factors of Escherichia coli are multiple and usually complex affecting pathogenicity in combination with one another. Common virulence factors are Surface hydrophobicity, Colonization factor, Capsule, Serum resistance, Resistance to phagocytosis, Mannose resistant haemaglutination (MRHA), Mannose sensitive haem-aglutination (MSHA), Haemolysins, Enterotoxins, Siderophores, production of Alpha haemolysis, Colicins, Aerobactin, Cytotoxic necrotizing factor and ability to adhere uroepithelial cell. ${ }^{[1,3,4]}$ These are currently defined as Uropathogenic Escherichia coli. Serum resistance is one of the virulence properties by which the bacteria resist killing by nor- 
mal human serum due to the lytic action of the complement system. ${ }^{[5]}$

It has long been known that human strains of Gram-negative bacteria are insensitive to the bactericidal action to normal human serum despite the presence in the serum of bactericidal anybody and complement. The nature of serum resistance remains obscure. ${ }^{[6]}$

The present study concerns isolation of Escherichia coli in urinary tract infection, its serum and resistance virulence factor, comparative study of serum resistant and serum sensitive Uropathogenic Escherichia coli with the antibiotic profile. ${ }^{[7-10]}$

\section{Aims \& Objectives}

1. Isolation of Escherichia coli in Urinary tract infection.

2. To determine the prevalence of Serum resistant Uropathogenic Escherichia coli.

3. To compare antimicrobial efficacy in Serum resistant and Serum sensitive Uropathogenic Escherichia coli.

\section{Subjects and Methods}

It is an observational study conducted in CAIMS General Hospital Karimnagar. A total of 100 urine specimens were collected from patients who were attending general medicine outpatient, suspected \& suffering from urinary tract infection. Study period from first August 2018 to $31^{\text {st }}$ July 20019 (12 months). By conventional techniques (Mackie \& Mc. Cartnety), Escherichia coli were isolated and identified. The isolated strains were subjected to serum resistance and antibiotic sensitivity.

A mid-stream urine sample was collected under sterile precautions. A urine sample was transported to the laboratory without delay. Macroscopic examination, the appearances of the specimen, the color of the specimen, whether it was clear or cloudy (turbid) was noted. By Semi-quantitative culture method 1920; Blood agar and MacConkey agar were used. The semi-quantitative technique of inoculation by standard loop, a Nichrome wire of SWG 28 was used to make a circular loop of $3.26 \mathrm{~mm}$ internal diameter, which can hold $0.004 \mathrm{ml}$ of urine which yields 400 colonies. The number of colonies was counted and this number was used to calculate the number of viable bacteria per $\mathrm{ml}$ of urine by following the Kass concept. ${ }^{[11]}$ The presence of active infection in the urinary tract that the urine will contain $10^{5}(1,00,000$ bacteria) or more per $\mathrm{ml}$. this level is, therefore, considered to represent significant bacteriuria. Counts of 10.000 bacteria (or) less per $\mathrm{ml}$ are due to contamination during voiding and are of no significance. Microscopic examination of a wet film of un-centrifuged urine was done to detect the presence of pus cells (Pyorrhea) and red blood Corpuscles (haematuria) an indication of infection in the urinary tract.
After incubation, MacConkey agar plates were observed for lactose fermenters and blood agar plates beta hemolysis. Colonies were counted on each plate. The number of colonies forming units was multiplied by $400(0.004 \mathrm{ml}$ holding loop was used) to determine the number of microorganisms per $\mathrm{ml}$ in the original specimen. A single isolated colony was picked up with a sterile wire loop to prepare a smear for Gram's stain for Gram negative bacteria and for the preparation of hanging drop to observe the motility.

Catalase test, ${ }^{[12]}$ the production of gas bubbles from the surface of the solid culture material indicates a positive reaction. It occurs almost immediately. A false-positive reaction may be obtained if the culture medium contains Catalase (e.g Blood agar) or an Iron wire loop was used.Positive -Effervescence or air bubbles are seen. Negative - No Effervescence or No air bubbles are seen. Positive control- Escherichia coll. Negative control- Streptococci.

Oxidase test, ${ }^{[12]}$ Dry filter paper method-Freshly prepared Oxidase strip was taken, laid in a Petri dish and moistened with distilled water colony to be tested was picked up with a platinum loop and smear over the moist area. A positive reaction indicated by an intense deep purple-blue, appearing within 5-10 seconds. A delayed positive reaction by the absence of coloration or by coloration later 60 seconds. Positive control- Pseudomonas aeruginosa. Negative control Escherichia coli.

A single colony was inoculated into peptone water incubated at $37^{\circ} \mathrm{C}$ for 4 hours and turbidity matched with McFarland 0.5 standard. ${ }^{[7]}$ The broth was inoculated onto sugars Glucose, Lactose, Sucrose, Xylose, Maltose, Mannitol, Triple Sugar Iron (TSI) and special sugars Indole test, Methyl red test, Voges-Proskauer test, Citrate utilization test, Urea hydrolysis test, all the sugars are incubated at $37^{\circ} \mathrm{C}$ for overnight. Triple sugar iron agar (tsi agar) test for $\mathrm{H}_{2} \mathrm{~S}$ production, ${ }^{[13]}$ Heavy inoculum from the broth was taken, first stabbed into the butt and streaked over the surface of the slope. Incubated aerobically at $37^{\circ} \mathrm{C}$ for 24 hours. Serum resistance is for isolated E Scherichia coli.

The resistance of the bacteria to serum bactericidal activity was expressed as a percentage of bacteria surviving after 180 minutes of incubation with serum about the original count.

- The bacteria are termed serum sensitive if the count drops to $1 \%$ of initial value and resistance if more than $90 \%$ of organisms survive after 180 minutes.

\section{- Antimicrobial susceptibility test. [14,15]}

The organism was tested for antibiotic sensitivity on MuellerHinton agar by Kirby-Bauer disc diffusion method according to National Committee for Clinical Laboratory Standards (NCCLS) criteria.A lawn culture was made by swab three times turning the plate at a $60^{\circ}$ angle between each streaking on 
Mueller-Hinton agar. The plates were kept for 5 to 15 minutes to dry the inoculum with the lid in place.

Application of the disc; Antibiotic impregnated commercially prepared $6 \mathrm{~mm}$ diameter filter paper discs were used, gently under sterile conditions with sterile forceps discs were placed flat on the surface of the agar plate and firmly applied to ensure adhesion. The discs should preferably be deposited with the center at least 18 to $20 \mathrm{~mm}$ apart.

The following antibiotics were used for testing antimicrobial susceptibility. ${ }^{[1,5]}$

Amikacin(30 $(3 \mathrm{~g})$, Ampicillin $(10 \mu \mathrm{g})$, Cephotaxime $(30 \mu \mathrm{g})$, Cefepime $(30 \mu \mathrm{g})$, Cefixime $(5 \mu \mathrm{g}), \quad$ Ceftazidime/Clavulanic acid $(30 / 10 \mu \mathrm{g})$, Ciprofloxacin $(30 \mu \mathrm{g})$, Gentamicin $(10 \mu \mathrm{g})$, Netilmicin $(30 \mu \mathrm{g})$, Nitrofurantino $(100 \mu \mathrm{g})$, Nalidixic acid (30 $\mu \mathrm{g})$ 'Norfloxacin $(10 \mu \mathrm{g})$, Ofloxacin $(5 \mu \mathrm{g})$.

Interpretation of the results, ${ }^{[15]}$ The plates were examined after 18 hours of incubation, the zone of inhibition around the disc was measured with the help of a millimeter ruler and the results were interpreted as sensitive, resistant according to NCCLS guidelines.

The data is collected and entered in the Microsoft excel 2010 for further analysis, data were analyzed by using statistical software for social sciences (SPSS) Ver. 25. Qualitative data were presented in the form of proportion and the chi-square test was used to see the difference in the proportion.

\section{Results}

The present work was carried out in the Department of Microbiology CAIMS, Bommakal, Karimnagar, from $1^{\text {st }}$ April 2018 to $31^{\text {st }}$ March 2009 (12 months period).

The total number of urine samples was 100 included in the present study.

Out of 100 urine samples 71 Uropathogenic Escherichia coli were isolated. Among them 18 isolates from males and 53 isolates from the female. The uropathogenic distribution between males and females was statistically highly significant at a $1 \%$ level of Significance. (P-value $<0.01)$

From the 71 Uropathogenic Escherichia coli isolates 28 (39.44\%) were resistant to serum (SREC) and $43(60.70 \%)$ isolates sensitive to serum. Among SREC Females 22 (78.57\%) Males 6 (21.43\%) Total SSEC Females12 (27.91\%) Males 31 (72.09\%)

7 Uropathogenic Escherichia coli were isolated from the 2 to 18 years age group. Among them 5 (71.43\%) males $2(40 \%)$ were resistant $3(60 \%)$ were sensitive to serum and $2(28.57 \%)$ females. $1(50 \%)$ was serum resistant and $1(50 \%)$ was serum sensitive.

19 to 40 years age group 36 Uropathogenic Escherichia coli were isolated. In these 3 isolates from male 1 (33.33\%) was



Figure 1: Incidence of serum resistant and serum sensitive Escherichia coli

resistant and $2(67.77 \%)$ were sensitive and 33 isolates from females. $10(30.30 \%)$ were serum resistant and $23(69.70 \%)$ were serum sensitive.

40 years age group 28 Uropathogenic Escherichia coli were isolated. Among them 10 isolates from males and $3(30 \%)$ were resistant to serum and $7(70 \%)$ were sensitive to serum. And among 18 isolates from females, 11 (61.11\%) were resistant to serum and $7(38.89 \%)$ were sensitive to serum.

Serum resistant Uropathogenic Escherichia coli is resistant to Ampicilin, Gentamicin, Cefepime, Ofloxacin, Cefexime, Norfloxacin, Ciprofloxacin, Cefatazidime / Calvulanic acid and sensitive to Nitrofurantoin, Amikacin, Netilmicin, Nalidixic acid Cephotaxime.

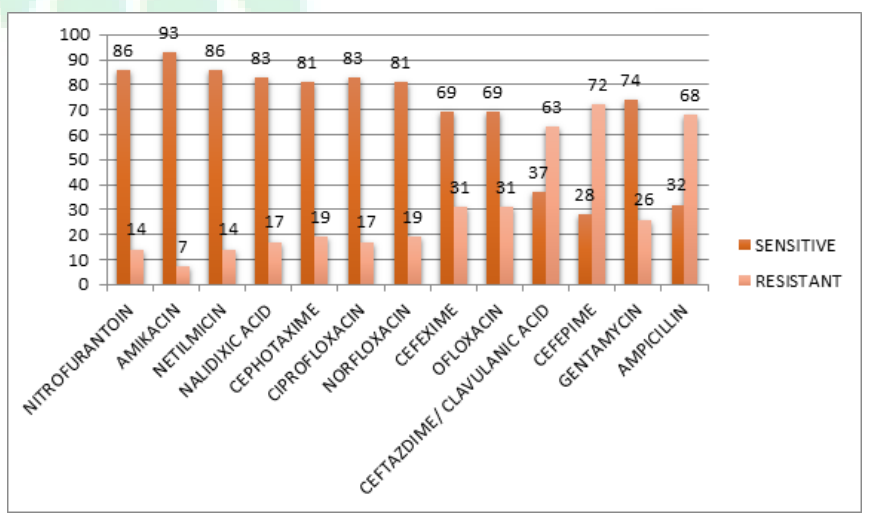

Figure 2: Antibiotic pattern in serum sensitive Escherichia coli

For all antibiotics the difference between the proportion of sensitivity and resistivity was statistically highly significant which is $<0.001$ at a $1 \%$ level of significance 


\begin{tabular}{|l|llll|}
\hline \multicolumn{2}{|l|}{ Table 1: Gender Distribution of isolated cases. } & & & \\
\hline $\begin{array}{llll}\text { Total no. of urine } \\
\text { specimens }\end{array}$ & $\begin{array}{l}\text { Total of no. } \\
\text { Uropathogenic } \\
\text { Escherichia coli isolates }\end{array}$ & Males & Females & p-value (Chi-square) \\
100 & $71(71 \%)$ & $18(25.35 \%)$ & $53(74.65 \%)$ & $<0.001$ \\
\hline
\end{tabular}

Table 2: Shows age vs sex and its serum resistance \& serum sensitivity E.Coli

\begin{tabular}{llll}
\hline Age Group & SEX & SREC & SSEC \\
\hline $2-18$ years & Male (5) & $2(40 \%)$ & $3(60 \%)$ \\
& Female (2) & $1(50 \%)$ & $!(50 \%)$ \\
\hline 19-40years & male (3) & $1(33 \%)$ & $2(67 \%)$ \\
\hline \multirow{2}{*}{ Above 40years } & Female (33) & $10(30 \%)$ & $23(70 \%)$ \\
& Male (10) & $3(30 \%)$ & $7(70 \%)$ \\
\hline
\end{tabular}

P-value $=0.1416>0.05$ at $5 \%$ level of Signficance, which is not significant

\section{Table 3: Antibiotic pattern in serum resistant Escherichia coli}

\begin{tabular}{|c|c|}
\hline Resistant & Sensitive \\
\hline Ampicillin - 24 (88\%) & Nitrofurantoin $-19(70 \%)$ \\
\hline Gentamicin $-23(85 \%)$ & Amikacin - $18(60 \%)$ \\
\hline Cefepime - 23(85\%) & Netilmicin - $16(59 \%)$ \\
\hline Ofloxacin - $21(74 \%)$ & Nalidixic acid - $16(59 \%)$ \\
\hline Cefexime - $20(74 \%)$ & Cephotaxime - $12(44 \%)$ \\
\hline \multicolumn{2}{|l|}{ Norfloxacin - $19(71 \%)$} \\
\hline \multicolumn{2}{|l|}{ Ciprofloxacin - $17(63 \%)$} \\
\hline Cefetazidime/ Clavulanic acid - $6(21 \%)$ & \\
\hline
\end{tabular}

Serum sensitive Uropathogenic Escherichia coli resistant to Cefepime 31 (72\%), Ampicilin 29 (68\%), Cefatazidime/ Calvulanic acid 27(63) and sensitive to Amikacin 40(93\%), Nitrofurantoin37(86\%), Netilmicin 37(86\%), Nalidixic acid 36 (83\%), Ciprofloxacin 36(83\%), Norfloxacin35 (81\%), Cephotaxime 35(81\%), Gentamicin 32 (74\%), Cefexime 30 $(69 \%)$ and Ofloxacin 30(69\%).

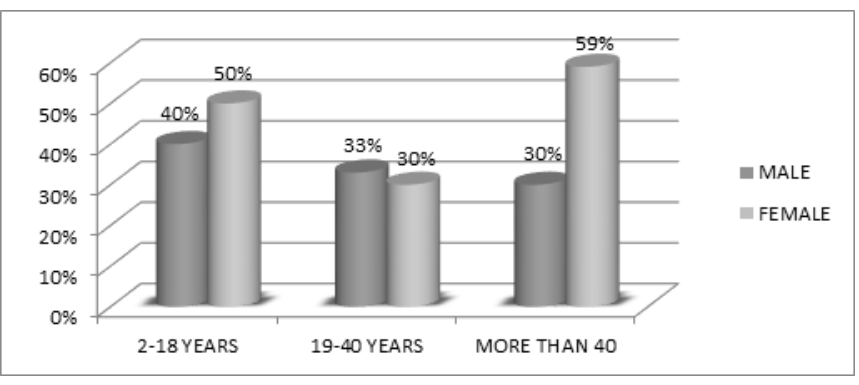

Figure 3: Serum resistant Escherichia coli in different age groups Vs sex groups
2 to 18 years of age groups of the male are more susceptible to serum resistance compared to other group males. More than 40 years of the age group of the female are more susceptible to serum resistance compared to other group females.

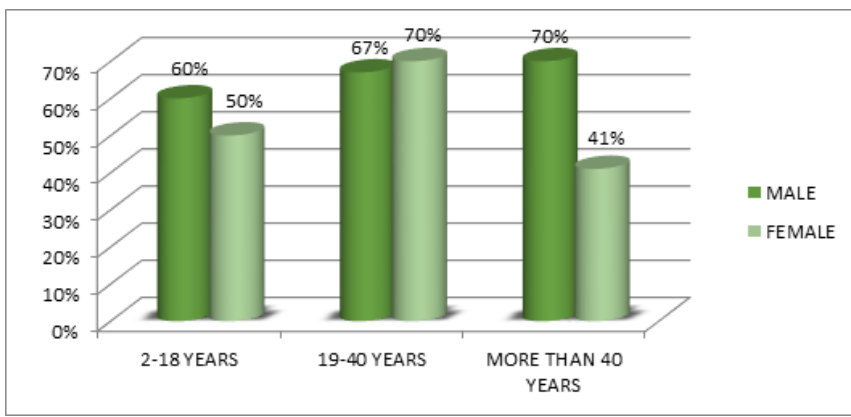

Figure 4: Serum sensitive Escherichia coli in different age groups Vs sex groups 
More than 40 years of the age group of the male are susceptible to serum sensitive compared to another group of male. Age groups between 19 to 40 years female are more susceptible to serum sensitivity compared to another age group of females.

\section{Discussion}

The present study was carried out from August 2018 to July 2019 in the hospital and the Department of Microbiology, CAIMS, Karimnagar.

Among 100 urine samples, 71 Uropathogenic Escherichia coli were isolated. Out of 71 Uropathogenic Escherichia coli 28 (39\%) were serum resistant, 43 (61\%) were serum sensitive.

A similar study was done by G. Bugle-Plaskonska et al, ${ }^{[10]}$ in 2006 observed $40 \%$ serum resistant Escherichia coli, $60 \%$ serum sensitive Escherichia coli. Their results are similar to the present results.

Another study by Yasmeen Kauser et al, ${ }^{[1]}$ in 2009 reported 49.5\% serum resistant Escherichia coli, 50.5\% scrum sensitive Escherichia coli. They reported more serum resistant Escherichia coli compared to the present study results.

A similar study done by L. Siegfried et al, ${ }^{[9]}$ in 1992 reported $21.62 \%$ serum resistant Escherichia coli, 78.37\% serum sensitive Escherichia coli. Their findings are nearly similar to the present findings.

Another study done by L. Siegfried et al, ${ }^{[4]}$ in 1995 reported $42.80 \%$ serum resistant Escherichia coli, and $57.14 \%$ serum sensitive Escherichia coli. Their observation is similar to the present observation.

A similar study conducted by R. Raksha et al, ${ }^{[2]}$ in 2003 investigated 32.72\% serum resistant Escherichia coli, 67.27\% serum sensitive Escherichia coli. Their study is nearly similar to the present study.

Another study done by A.P Roberts et al, ${ }^{[12]}$ in 1983 studied 50\% serum resistant Escherichia coli, 50\% serum sensitive Escherichia coli. Serum resistance is higher; serum sensitivity is less in their study than the present study.

A similar study done by Savithri Sharma et al, ${ }^{[5]}$ in 2007 investigated $86.7 \%$ serum-resistant Escherichia coli, 13.3\% serum sensitive Escherichia coli. In their findings serum resistant Escherichia coli are more, and serum sensitive Escherichia coli are less than the present study findings.

\section{Conclusion}

A total number of 100 urine samples from the patients attending CAIMS General Hospital form the material for the study. 71 Escherichia coli were isolated out of 100 urine samples.
In our study out of 71, Escherichia coli $39 \%$ were serum resistant and $61 \%$ were serum sensitive. The study shows that Serum resistant Escherichia coli are more multiple drug-resistant (Ampicilin, Gentamycin, Cefepime, Ofloxacin, Cefexime, Norfloxacin, Ciprofloxacin, Cefatazidime/ Clavulanic acid) compare to serum sensitive Escherichia coli (which are resistant to Cefepime, Ampicilin, Cefatazidime/ Clavulanic acid).

It emphasizes Serum resistance is an important virulence factor in Uropathogenic Escherichia coli. It may lead to an invasive infection such as pyelonephritis and urinary tract derived septicemia. The present study is useful in formulating guidelines to treat serum resistant Escherichia coli Therefore periodic surveillance is required to monitor resistance pattern in Uropathogenic Escherichia coli for planning effective treatment strategies.

\section{References}

1. Kausar Y, Sneha K, Chunchanur, Shobha D, Nadagir L, Halesh $\mathrm{MR}$, et al. Virulence factors, sero types and antimicrobial susceptibility pattern of Escherichia coli in Urinary tract infections. Al Ameen J Med Sci. 2009;2(1):47-51.

2. Raksha R, Srinivasa H, Macaden RS. Occurrence and characterisation of Uropathogenic Escherichia coli in urinary tract infections. Indian J Med Microbiol. 2003;21(2):102-107.

3. Bhat GK, Mallya S, Hegde A. Effect of exposure to hydrogen peroxide on the virulence of $<\mathrm{i}><\mathrm{i}>$ Escherichia $</ \mathrm{i}>$ coli $</ \mathrm{i}>$. Indian J Med Microbiol. 2008;26(1):25-25. Available from: https://dx.doi.org/10.4103/0255-0857.38853.

4. Siegfried L, Kmetova M, Janigova V, Sasinka M, Takacova V. Serum Response of Escherichia coli Strains causing Dyspepsia and Urinary tract infection: Relation to Alpha_hemolysin production and O Type. Infect Immun. 1963;11:4543-4545.

5. Bhat GK, Shenoy S, Sharma S. Virulence factors and drug resistance in $<\mathbf{i}>$ Escherichia coli $</ \mathrm{i}>$ isolated from extraintestinal infections. Indian J Med Microbiol. 2007;25(4):369. Available from: https://dx.doi.org/10.4103/0255-0857.37341.

6. Taylor PW, Parton R. A Protein Factor Associated With Serum Resistance in Escherichia Coli. J Med Microbiol. 1977;10(2):225-232. Available from: https://dx.doi.org/10. 1099/00222615-10-2-225.

7. Kot B. Antibiotic Resistance Among Uropathogenic Escherichia coli. Pol J Microbiol. 2019;68(4):403-415. Available from: https://dx.doi.org/10.33073/pjm-2019-048.

8. Roberts A, Philips R. The relative importance of the classical and alternative complement pathways in Serum bacterial activity against Escherichia coli. Journal of Medical Microbiology. 1983;(16):69-74.

9. Siegfried L, Puzova H, Kmetcova M, Kerstesova A. Killing of $\alpha$-haemolytic and non-haemolytic Escherichia coli strains in human serum and polymorphonuclear leucocytes. J Med Microbiol. 1992;37(1):3-7. Available from: https://dx.doi.org/ 10.1099/00222615-37-1-3. 
10. Bugla-Płoskońska G, Cisowska A, Karpińska K, Jankowski S, Doroszkiewicz W. The mechanisms of activation of normal human serum complement byEscherichia coli strains with K1 surface antigen. Folia Microbiol. 2006;51(6):627-632. Available from: https://dx.doi.org/10.1007/bf02931630.

11. Primack W, Bukowski T, Sutherland R, Gravens-Mueller L, Carpenter M. What Urinary Colony Count Indicates a Urinary Tract Infection in children? J Pediatr. 2017;191:25961. Available from: https://dx.doi.org/10.1016/j.jpeds.2017.08. 012.

12. Iwase T, Tajima A, Sugimoto S, ichi Okuda K, Hironaka I, Kamata Y, et al. A Simple Assay for Measuring Catalase Activity: A Visual Approach. Sci Rep. 2013;3:3081. Available from: https://dx.doi.org/10.1038/srep03081.

13. Ma M, Amano T, Enokimoto M, Yano T, Moe KK, Misawa N. Influence of $\mathrm{pH}$ of TSI medium on the detection of hydrogen sulfide production by Campylobacter hyointestinalis. Lett Appl Microbiol. 2007;44(5):544-9. Available from: https://dx.doi. org/10.1111/j.1472-765X.2006.02097.x.

14. Jones RN, Glick T, Sader HS, Flamm RK, Ross JE, Rhomberg $\mathrm{PR}$, et al. Educational antimicrobial susceptibility testing as a critical component of microbiology laboratory proficiency programs: American Proficiency Institute results for 2007-2011.
Diagn Microbiol Infect Dis . 2013;75(4):357-60. Available from: https://dx.doi.org/10.1016/j.diagmicrobio.2013.01.027.

15. Syal K, Mo M, Yu H, Iriya R, Jing W, Guodong $S$, et al. Current and emerging techniques for antibiotic susceptibility tests. Theranostics. 2017;7(7):1795-1805. Available from: https://dx.doi.org/10.7150/thno.19217.

Copyright: (c) the author(s), 2020. It is an open-access article distributed under the terms of the Creative Commons Attribution License (CC BY 4.0), which permits authors to retain ownership of the copyright for their content, and allow anyone to download, reuse, reprint, modify, distribute and/or copy the content as long as the original authors and source are cited.

How to cite this article: Prakash K, Kumar JS, Rajamouli J, Gurnule S. A Study on Prevalence of Serum Resistant \& Sensitive Escherichia Coli in Urinary Tract Infection. Asian J. Med. Res. 2020;9(4):1-6.

DOI: dx.doi.org/10.47009/ajmr.2020.9.4.MB1

Source of Support: Nil, Conflict of Interest: None declared. 